\title{
Article \\ In Silico Analysis of Honeybee Venom Protein Interaction with Wild Type and Mutant (A82V + P375S) Ebola Virus Spike Protein
}

\author{
Muhammad Muzammal ${ }^{1}$, Muzammil Ahmad Khan ${ }^{1}$, Mohammed Al Mohaini ${ }^{2,3}{ }^{\mathbb{D},}$, Abdulkhaliq J. Alsalman ${ }^{4}$, \\ Maitham A. Al Hawaj ${ }^{5}$ and Arshad Farid ${ }^{1, *(D)}$
}

Citation: Muzammal, M.; Khan, M.A.; Mohaini, M.A.; Alsalman, A.J.; Hawaj, M.A.A.; Farid, A. In Silico Analysis of Honeybee Venom Protein Interaction with Wild Type and Mutant (A82V + P375S) Ebola Virus Spike Protein. Biologics 2022, 2, 45-55. https://doi.org/10.3390/

biologics2010003

Academic Editors: Vasso Apostolopoulos and Majid Hassanzadeganroudsari

Received: 12 December 2021

Accepted: 5 January 2022

Published: 7 January 2022

Publisher's Note: MDPI stays neutral with regard to jurisdictional claims in published maps and institutional affiliations.

Copyright: (C) 2022 by the authors. Licensee MDPI, Basel, Switzerland. This article is an open access article distributed under the terms and conditions of the Creative Commons Attribution (CC BY) license (https:// creativecommons.org/licenses/by/ $4.0 /)$.
1 Gomal Centre of Biochemistry and Biotechnology, Gomal University, Dera Ismail Khan 29050, Pakistan; mustafamuzammal1@yahoo.com (M.M.); m.ahmad@gu.edu.pk (M.A.K.)

2 Basic Sciences Department, College of Applied Medical Sciences, King Saud bin Abdulaziz University for Health Sciences, Alahsa 31982, Saudi Arabia; mohainim@ksau-hs.edu.sa

3 King Abdullah International Medical Research Center, Alahsa 31982, Saudi Arabia

4 Department of Clinical Pharmacy, Faculty of Pharmcay, Northern Border University, Rafha 91911, Saudi Arabia; KALIQS@gmail.com

5 Department of Pharmacy Practice, College of Clinical Pharmacy, King Faisal University, Alahsa 31982, Saudi Arabia; Hawaj@kfu.edu.sa

* Correspondence: arshadfarid@gu.edu.pk; Tel.: +92-3459844202

\begin{abstract}
Venom from different organisms was used in ancient times to treat a wide range of diseases, and to combat a variety of enveloped and non-enveloped viruses. The aim of this in silico research was to investigate the impact of honeybee venom proteins and peptides against Ebola virus. In the current in silico study, different online and offline tools were used. RaptorX (protein 3D modeling) and PatchDock (protein-protein docking) were used as online tools, while Chimera and LigPlot + v2.1 were used for visualizing protein-protein interactions. We screened nine venom proteins and peptides against the normal Ebola virus spike protein and found that melittin, MCD and phospholipase A2 showed a strong interaction. We then screened these peptides and proteins against mutated strains of Ebola virus and found that the enzyme phospholipase A2 showed a strong interaction. According to the findings, phospholipase A2 found in honeybee venom may be an effective source of antiviral therapy against the deadly Ebola virus. Although the antiviral potency of phospholipase A2 has been recorded previously, this is the first in silico analysis of honeybee phospholipase A2 against the Ebola viral spike protein and its more lethal mutant strain.
\end{abstract}

Keywords: honeybee; phospholipase A2; Ebola virus

\section{Introduction}

Venom is a toxic substance, which has a variety of different compounds, i.e., enzymes, peptides, amines, small organic molecules, alkaloids, minerals and salts. The mechanism of delivery of these compounds in the form of venom into the victim requires special apparatus such as fangs, or a spine or stinger. There are a variety of organisms that contain venom, i.e., insects, fish, reptiles, jellyfish, gastropods, echinoderms, amphibians, sea anemones, centipedes, cephalopods and five mammalian species. The composition of venom and its delivery system and their respective targets can be different from species to species [1,2].

Venom is present in different species of insect, but among them, honeybees, wasps and ants belong to the Hymenoptera order and are classified as venomous insects. Remarkably, a common parasitic ancestral origin is shared by the hymenopterans [1]. Numerous parasitoid wasps of the paraphyletic suborder use their terebra (stinging organ) to transfer their eggs outside or inside the body of invertebrate hosts. Additionally, depending on the type of venom and its host, venom can affect the host's immunity, physiology, capacity to reproduce, mobility and behavior [2,3]. 
Even within the same genus, the composition of venom in different parasitoids may vary between different species, showing their functional diversity during evolution. Only species belonging to three families prickle humans with a high frequency; these species include wasps (Vespidae), bees (Apidae) and ants (Formicidae). The common honeybee belongs to the family Apidae, "Apoidea superfamily", and has a specific system of stinging known as the hymenopteran venom system [3]. Hymenoptera stings, claimed to be a wonder of natural engineering, cause a systemic allergic response, when honeybees insert their stingers into predators or victims [2]. Reports have stated that MCD is a great antiinflammatory peptide and may act as an important candidate for the study of secretory mechanisms of inflammatory cells, such as basophils mast cells, and leukocytes. Different studies also documented that two major components of honeybees, i.e., melittin and PLA2, have antimicrobial potency and can be used as important anti-bacterial agents [2,3]. These bee venom (BV) proteins have their effects against different bacteria by producing pores in the bacterial membrane, leading to the lysis of bacterial cells. However, the antiviral potency of honeybee venom has not been documented much in the literature.

Venom in honeybees (bee venom) is a mixture of different biologically active compounds comprising small peptides, different enzymes and/or other many small molecules [4]. Bee venom enzymes include phospholipase A2, phospholipase B, hyaluronidase (having cytotoxicity) and further nontoxic hydrolytic enzymes, i.e., $\alpha$-glucosidase and phosphatase. In the case of venom peptides, honeybee venom contains two important peptides, namely, apamin and melittin. Besides these two peptides, bee venom contains many other small peptides, i.e., mast cell degranulating (MCD) and secapin peptides. Some of these peptides acts as cell-penetrating peptides and are used for lysis of the affected cells, while others are neurotoxins damaging the nervous system [4].

Ebola virus $(E B O V)$ is a type of filovirus, which contains a single-stranded RNA genome of about $19 \mathrm{~kb}$, that causes periodic outbreaks of fatal hemorrhagic fever in humans. In humans, EBOV was first identified in 1976. The high case-fatality ratio and self-limited nature of outbreaks mean that Ebola virus disease (EVD) is a zoonosis [5,6].

The West African outbreak of EBOV, from its beginnings in December 2013, has resulted in more than 27,000 confirmed cases and more than 10,000 human deaths according to data of the World Health Organization [7]. As with earlier outbreaks, the West African epidemic began following the successful cross-species transmission of EBOV into humans from an animal host, with an increasing indication that different species of bat are the possible natural host and are responsible for the transmission of the virus between human outbreaks [8].

The effective continuing spread of viruses in humans from other animal species is often related to gaining host-adaptive mutations [9]. Minor changes in the EBOV spike protein (SP) can influence its skills to facilitate viral entry into cells from diverse mammalian species, such that it is clearly a main element of host specificity and viral fitness [10]. Though the development of EBOV during the outbreak was considered to be caused by the transmission of genetically diverse viral mutations [11-16], it is still unclear whether this prolonged human transmission enabled the virus to adapt to completely human transmission.

Though researchers have recorded different nonsynonymous mutations during the pandemic, which have probably had a slight effect on viral fitness, it is still probable that a few of these mutations multiplied because they provide a benefit to the virus. One such candidate is the clade-defining Ala82Val (A82V) substitution in the EBOV SP, which occurred at a time in the epidemic. This mutation is particularly interesting because it is located in the EBOV receptor-binding domain [6].

Honeybee venom contains different types of proteins that have antimicrobial activity, i.e., melittin. Therefore, the main aim of the current in silico study was to investigate the impact of these antimicrobial compounds on wild-type and mutant Ala82Val + Pro375Ser $(\mathrm{A} 82 \mathrm{~V}+\mathrm{P} 375 \mathrm{~S}) \mathrm{EBOV}$ spike proteins (SPs). 


\section{Results}

\section{Homology Modeling}

Three-dimensional models of nine honeybee venom peptides and proteins, i.e., apamin (Uniprot ID\# B7UUK0, 46 amino acid-long peptide), melittin (Uniprot ID\# P01501, 70 amino acid-long peptide), mast cell degranulating peptide (MCD) (Uniprot ID\# P01499, 50 amino acid-long peptide), secapin (Uniprot ID\# I1VC85, 77 amino acid-long peptide), alkaline phosphatase (Uniprot ID\# A0A7M7GX77, 534 amino acid-long protein), alpha-glucosidase (Uniprot ID\# Q17058, 581 amino acid-long protein), hyaluronidase (Uniprot ID\# Q08169, 382 amino acid-long protein), phospholipase B-like (Uniprot ID\# A0A7M7R5W3, 544 amino acid-long protein) and phospholipase A2 (Uniprot ID\# P00630, 167 amino acid-long protein), were constructed, as shown in Figure 1.

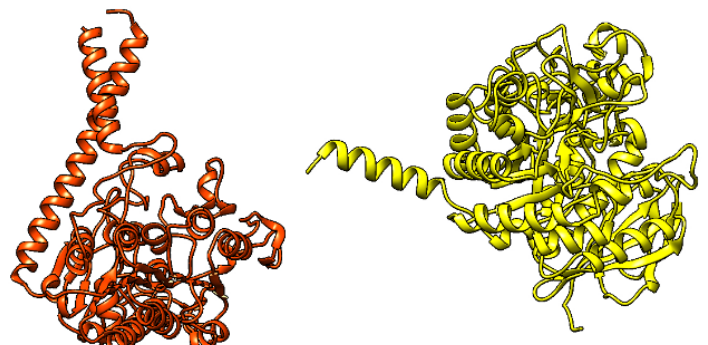

Alkaline phosphatase

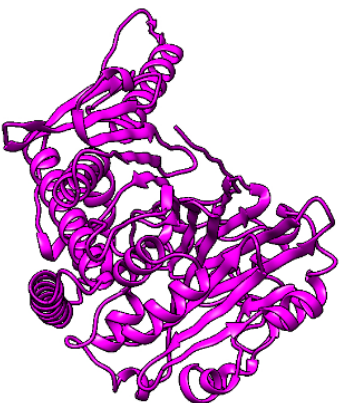

Phospholipase B-like
Alpha-glucosidase

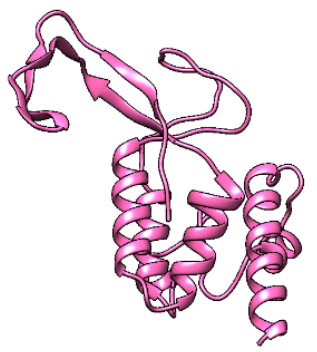

PA2 Apime Phospholipase
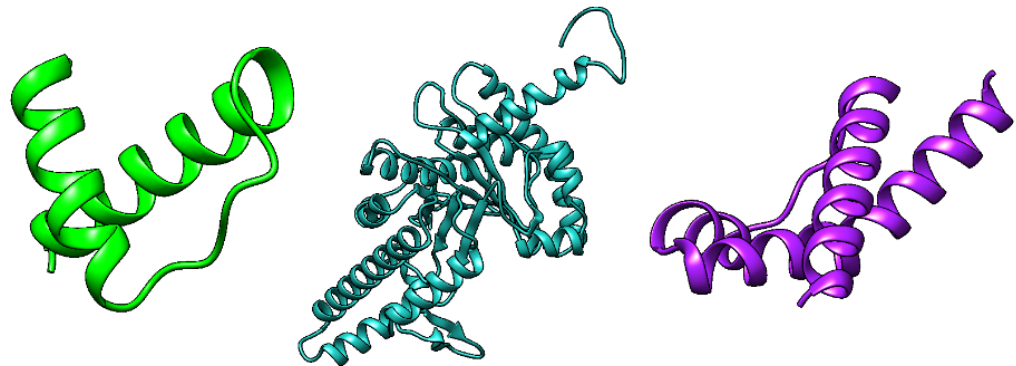

\section{Apamin}

Huga_Apime Hyaluronidase
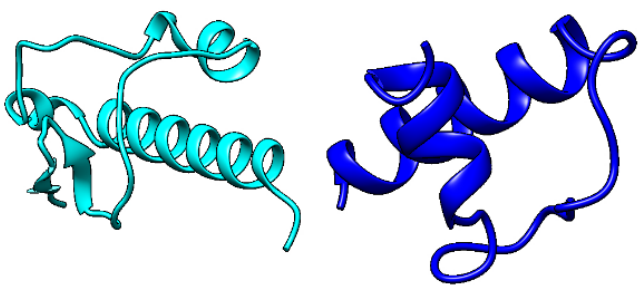

Secapin

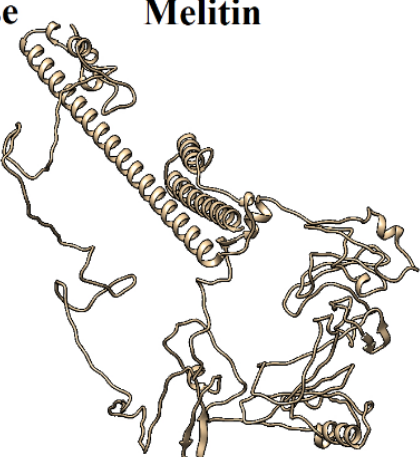

Ebola Virus S-Protein

Figure 1. Three-dimensional models of normal Ebola viral spike protein and honeybee venom proteins.

Additionally, normal and mutant (A82V + P375S) EBOV spike protein 3D models were designed and superimposed. As expected, the similarity index of the normal and mutant (A82V + P375S) EBOV spike protein 3D models was only $0.44 \%$, and different changes in the folding of the protein were noted in the normal and mutated EBOV proteins, as shown in Figure 2.

Although different changes were noted in the structure of the normal and mutated EBOV proteins, one of the major changes includes the finding that the mutant $(\mathrm{A} 82 \mathrm{~V}+\mathrm{P} 375 \mathrm{~S})$ protein had new strands at amino acid positions Arg219-Thr223 and Glu231-Glu235, and these strands were absent in the normal EBOV protein. The mutant protein had many new small helices at different positions, which were absent in the normal viral protein, i.e., Arg11Phe14, Phe151-His154, Pro209-Ser211, Pro279-Ile281, ILE341-Ala341 and Asn461-Asn463. The normal viral protein had four small strands in its structure, which were absent in the mutated viral protein, i.e., Val169-Tyr171, Thr174-Phe176, Val351-His354 and Glu359-Val362 (Figure 2).

In the first step, we examined the interaction of honeybee venom proteins, i.e., apamin, melittin, MCD, secapin, alkaline phosphatase, alpha-glucosidase, hyaluronidase, phospholipase B-like and phospholipase A2, with the normal viral protein. Apamin interacted with the normal viral protein through four different bonds with four different residues (three 
hydrogen bonds and one salt bridge). Melittin interacted with the normal viral protein through five bonds with four different residues (all hydrogen bonds). The MCD protein interacted with the normal viral protein through six bonds with four different residues (all hydrogen bonds). Secapin interacted with the normal viral protein through three hydrogen bonds with three different residues, as shown in Figure 3.

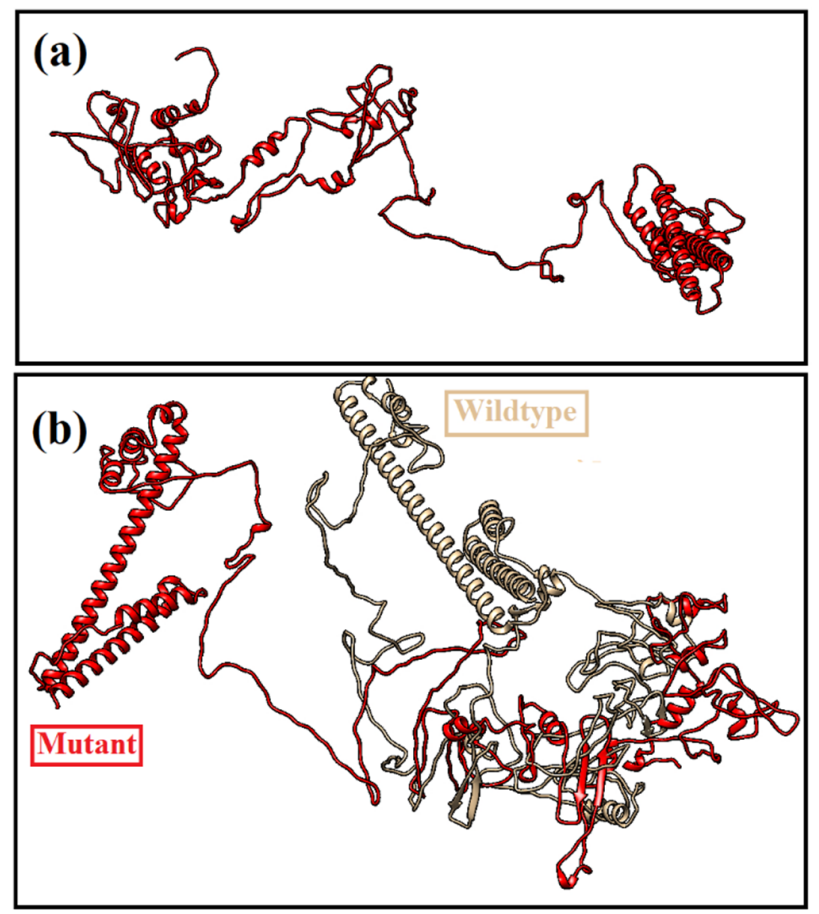

Figure 2. (a) Three-dimensional model of mutated (A82V + P337S) Ebola virus spike protein, and (b) superimposed structure of mutated and normal Ebola virus proteins.

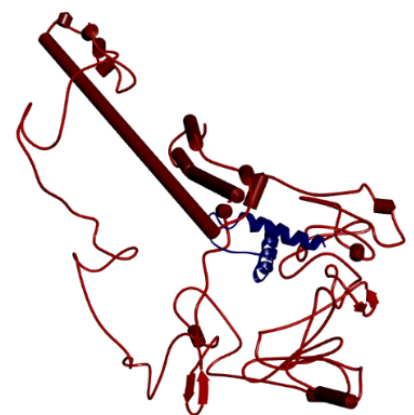

(a)

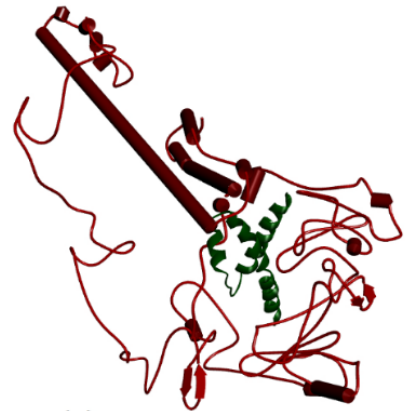

(c)

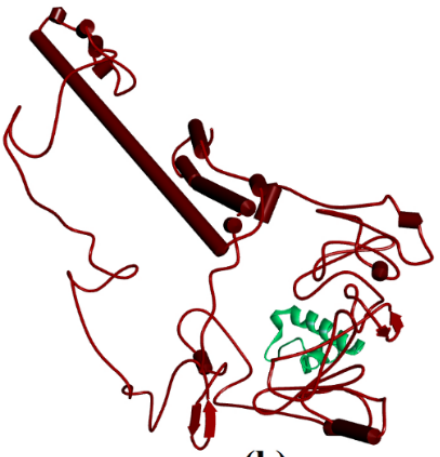

(b)

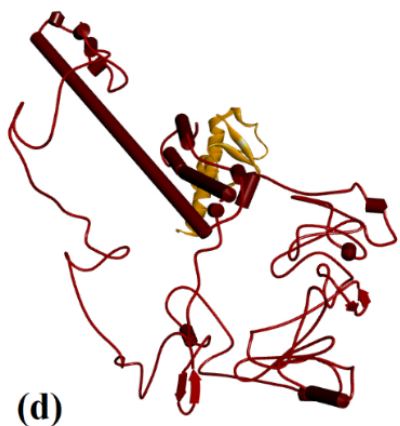

Figure 3. (a) Apamin and normal Ebola viral spike protein interaction; (b) MCD and normal Ebola viral spike protein interaction; (c) melittin and normal Ebola viral spike protein interaction; (d) secapin and normal Ebola viral spike protein interaction. 
However, no interaction was noted between the normal viral protein and the alkaline phosphatase enzyme. Alpha-glucosidase interacted with the normal viral protein through two different bonds with two different residues (one hydrogen bond and one salt bridge). Only a single hydrogen bond interaction was noted between the normal viral protein and the phospholipase B-like enzyme. The hyaluronidase enzyme interacted with the normal viral protein through two different bonds with two different residues (one hydrogen bond and one salt bridge), and phospholipase A2 interacted with the normal viral protein through four bonds with four different residues (all hydrogen bond interactions), as shown in Figure 4. Therefore, in the case of bee venom (BV) enzymes, a strong interaction was shown by the phospholipase A2 enzyme. Integration of the residues of the normal EBOV protein and honeybee venom proteins is summarized in Table 1.

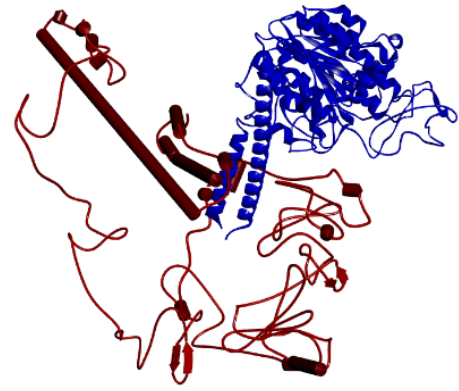

(a)

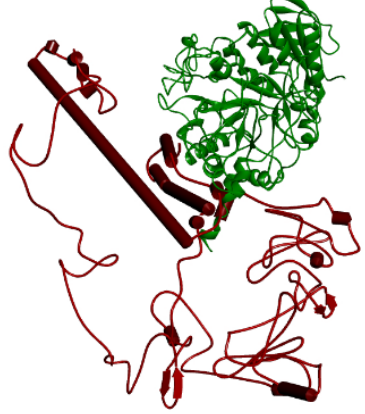

(b)

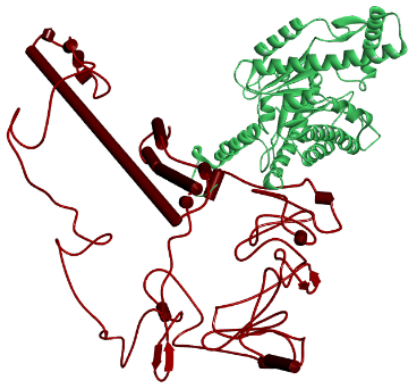

(c)

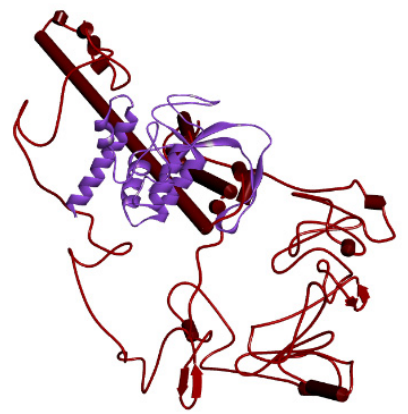

(d)

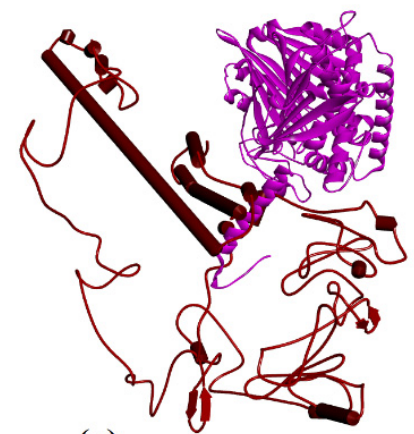

(e)

Figure 4. (a) Interaction of honeybee venom protein alkaline phosphatase with normal Ebola viral spike protein. (b) Interaction of honeybee venom protein glucosidase with normal Ebola viral spike protein. (c) Interaction of honeybee venom protein hyaluronidase with normal Ebola viral spike protein. (d) Interaction of honeybee venom protein phospholipase A2 with normal Ebola viral spike protein. (e) Interaction of honeybee venom protein phospholipase B with normal Ebola viral spike protein.

Among all the tested honeybee venom proteins, two peptides, i.e., MCD and melittin, and phospholipase A2 showed a strong interaction with the normal EBOV spike protein, and thus we further investigated these three (i.e., MCD, melittin and phospholipase A2) proteins and checked their interaction with the mutant and more virulent strain of EBOV, i.e., A82V + P335S.

Among these test proteins, melittin and phospholipase A2 are considered to have antimicrobial activity, while the MCD peptide is reported to have anti-inflammatory activity. During the investigation, we found that the proteins, which showed a strong interaction in the case of the normal EBOV spike protein, showed a very weak interaction with the mutant viral protein, and both MCD and melittin showed an interaction with the mutant strain with two hydrogen bonds through two different residues. Residues of melittin and the mutant viral strain that interacted include Lys2 and Val10, and Asp624 and Asp643, respectively. 
Meanwhile, in the case of the MCD protein and the viral mutant strain, interacting residues were Lys33 and Ser3, and Glu112 and Asp150, respectively (Figure 5 and Table 1).

Table 1. Name and number of interacting residues between honeybee venom peptides and proteins and Ebola virus spike protein.

\begin{tabular}{|c|c|c|c|}
\hline Interacting Proteins & Wild-Type Ebola Virus Spike Protein Residues & Honeybee Venom Protein Residues & No. of $\mathrm{H}$ Bonds \\
\hline Apamin + Viral protein & Asn107, Glu103, His602 & Gln43, Arg40, Leu12 & $3+1 *$ \\
\hline Melittin + Viral protein & $\begin{array}{l}\text { His602, Arg130, Leu7, Lys15, } \\
\text { Arg13 }\end{array}$ & $\begin{array}{l}\text { Glu42, Tyr18, } \\
\text { Ala28, Glu38 }\end{array}$ & 5 \\
\hline MCD + Viral protein & $\begin{array}{l}\text { Phe183, Tyr162, Phe160, } \\
\text { Arg172, Trp288 }\end{array}$ & $\begin{array}{l}\text { Lys33, Ser3, Arg6, } \\
\text { Met4 }\end{array}$ & 6 \\
\hline Secapin + Viral protein & Gly72, Trp22, Asp642 & Arg71, Arg60, Gln49 & 3 \\
\hline Alkaline phosphatase + Viral protein & No interaction & & - \\
\hline Alpha-glucosidase + Viral protein & Asp607 & Arg214, Arg215 & $1+1 *$ \\
\hline Hyaluronidase + Viral protein & Thr42, Asp47 & Arg312, Asn366, & $1+1 *$ \\
\hline Phospholipase B-like + Viral protein & Ile38 & Arg192 & 1 \\
\hline Phospholipase A2 + Viral protein & $\begin{array}{l}\text { Cys672, Asp607, His602, } \\
\text { Ser32 }\end{array}$ & $\begin{array}{l}\text { Tyr149, Lys153, } \\
\text { Glu140, Thr150 }\end{array}$ & 4 \\
\hline Interacting Proteins & $\begin{array}{l}\text { Mutant (A82V + P375S) Ebola Virus Spike Protein } \\
\text { Residues }\end{array}$ & Honeybee Venom Protein Residues & No. of $\mathrm{H}$ Bonds \\
\hline Melittin + Mutated viral protein & Asp624, Asn643 & Lys2, Val10 & 2 \\
\hline MCD + Mutated viral protein & Glu112, Asp150 & Lys33, Ser3 & 2 \\
\hline Phospholipase A2 + Mutated viral protein & $\begin{array}{l}\text { Thr83, Asn257, Tyr261, } \\
\text { Leu9, Asn228, Ser263 }\end{array}$ & $\begin{array}{l}\text { Glu29, Asp95, Lys130, Ser79, His133, } \\
\text { Ser49 }\end{array}$ & 9 \\
\hline
\end{tabular}

* Salt bridge.

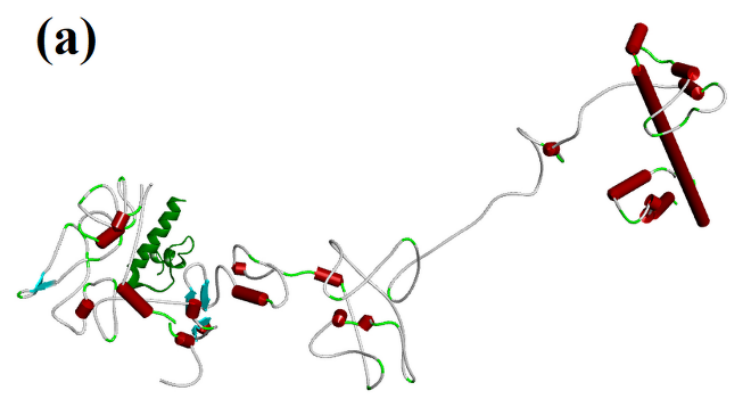

(b)
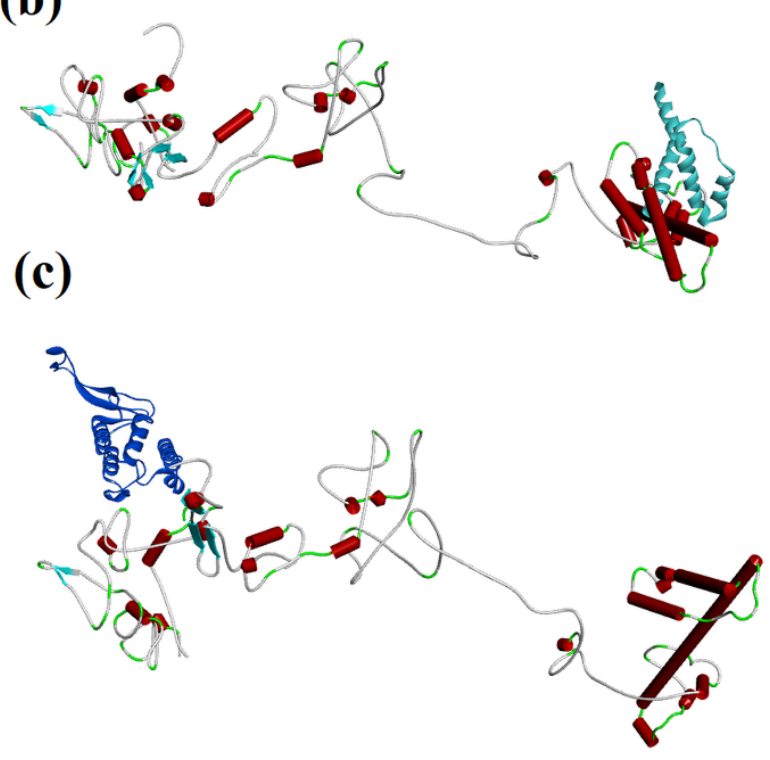

Figure 5. Interaction of honeybee venom peptides (a) melittin and (b) MCD and protein (c) phospholipase A2 with mutated (A82V + P337S) Ebola viral spike protein.

These results were as expected, even with the honeybee venom antimicrobial proteins, i.e., melittin, showing a weak interaction because of the high virulence of the mutant viral stain. In the case of the phospholipase A2 enzyme, it showed a strong interaction 
with the mutant viral strain with nine hydrogen bonds through six different residues. Phospholipase A2 and the mutant viral protein interacting residues were Glu29, Asp95, Lys130, Ser79, His133 and Ser49, and Thr83, Asn257, Tyr261, Leu9, Asn228 and Ser263, respectively (Figure 5 and Table 1 ).

\section{Discussion}

Currently, traditional antiviral vaccines and drugs are not enough to control the increasing number of viral diseases [17]. Thus, the discovery of new antiviral vaccines is necessary. In general, antiviral therapy is the only method to precisely treat viral infections, revoking viral replication $[18,19]$. However, due to the high number of genetic mutations, especially in RNA viruses, viruses can quickly obtain resistance to antiviral therapies $[4,20,21]$. For thousands of years, all honeybee products have been used, especially honey and venom, and their medicinal properties have been cited in religious books such as the Quran [22].

The MCD peptide, also recognized as peptide 401 , is a polypeptide and has a similar structure to another venom peptide known as apamin (shown in Figure 1). MCD accounts for $3 \%$ of the bee venom dry weight. Animal studies showed that MCD could reduce the blood pressure in rats. MCD is an epileptogenic neurotoxin, and it is an important inhibitor of potassium channels in rats.

Reports stated that MCD is a great anti-inflammatory peptide and may act as an important candidate for the study of secretory mechanisms of inflammatory cells, such as basophil mast cells, and leukocytes. Different studies also documented that two major components of honeybees, i.e., melittin and PLA2, have antimicrobial potency and can be used as important anti-bacterial agents [23-25]. These bee venom (BV) proteins have their effects against different bacteria by producing pores in the bacterial membrane, leading to the lysis of bacterial cells. However, the antiviral potency of honeybee venom has not been documented much in the literature. One study documented both in vivo and in vitro antiviral effects of BV and reported remarkable results. Studies showed that BV and especially the important BV peptide melittin have important antiviral effects against many enveloped viruses, e.g., influenza A virus, vesicular stomatitis virus and herpes simplex virus, and non-enveloped viruses, e.g., Coxsackie virus and enterovirus-71 [26]. One study also found that mice exposed to high doses of influenza A virus were protected with melittin [26].

Though the exact mode of action by which melittin in BV acts as an antiviral agent remains unclear, it has been confirmed that $\mathrm{BV}$ attaches directly to the surface of the virus. Additionally, BV and its peptides can enhance type I interferon (IFN) and therefore destroy viral replication in the host cell. Researchers in St. Louis from the Washington University School of Medicine have described the possible use of nanoparticles filled with melittin for killing HIV, keeping normal cells unharmed [27]. They have proposed a defensive approach in which these nanoparticles are used in developing a vaginal gel that prevents the spread of HIV. Another study showed that BV's phospholipase A could also block the replication of the virus. The same team further identified the peptide sequence of BV's PLA2 that is responsible for the control of HIV replication. Studies have documented that snake venom phospholipase enzymes (PLA2s) have shown important antiviral potency against different viruses, e.g., dengue virus, yellow fever virus, HIV and HCV, and can be considered as an alternative strategy for the advancement of novel antiviral vaccines. Phospholipase enzyme families are widely spread in nature and comprise hydrolase enzymes, which are vital for the metabolism of phospholipids and for membrane lipid regulation, intercellular signaling, inflammation and digestion [27]. Phospholipase enzymes are categorized into four main families, i.e., A, B, C and D, based on their activity and the site that is cleaved in the phospholipid molecule. Among these enzyme families, the most studied group is the phospholipases A2 (PLA2s) [2,28]. These enzymes break the "2-acyl ester bond to 2-snphospholipids" and release free fatty acids (arachidonic acid) and lysophospholipids. The free fatty acids (arachidonic acid) can again be converted into eicosanoids, i.e., prosta- 
cyclins, prostaglandins, thromboxanes and leukotrienes, which are related to a variety of biological effects, such as platelet activation and inflammation [28].

While working with diverse sPLA2s isolated from Crotalus durissus (rattle snake) venom, researchers discovered different methods to disclose the powerful antiviral potency mediated by PLA2-CB, crotoxin and PLA2-IC against the dengue and yellow fever viruses (enveloped viruses) [3].

In our study, PLA2 interacted with the viral protein through different residues, and among them, one of the interacting residues was Ser49. Previous research on PLA2 isolated from snake venom reported that Lys49 $\mathrm{PLA}_{2} \mathrm{~s}$ are devoid of catalytic activity due to their inability to bind $\mathrm{Ca}^{2+}$, a key cofactor for $\mathrm{PLA}_{2}$ activity. Despite the lack of enzymatic activity, Lys49 $\mathrm{PLA}_{2}$ homologues have been shown to display toxicity, especially myotoxicity [29]. The toxicity of Lys49 proteins can be related to a cluster of cationic and hydrophobic/aromatic amino acid residues located at the C-terminal region of these toxins.

In another study, researchers reported that BlK-PLA 2 (Lys49 sPLA 2 s) and BID-PLA 2 $\left(\right.$ Asp $49 \mathrm{sPLA}_{2} \mathrm{~s}$ ) are two basic sPLA 2 s isolated from Bothrops leucurus venom, a pit viper commonly found in the northeast of Brazil. Cecilio and coworkers [30] showed that the pretreatment of LLC-MK2 cells (rhesus monkey kidney epithelial cells) with each isoform of Bl-PLA ${ }_{2}$ followed by viral infection was able to inhibit DENV infectivity.

Previously, according to the myotoxic mechanism of Lys49 PLA $_{2}$ s from viperid snake venoms, it was proposed that the fatty acids which are important to protein activation may come from membrane phospholipid hydrolysis by catalytic $\mathrm{PLA}_{2} \mathrm{~S}$ (Asp49), highlighting the synergism between Asp49 PLA $_{2} \mathrm{~S}$ and Lys49 PLA $_{2}$ in snake envenomation [31]. In this way, the antiviral effects of the Lys49 $\mathrm{PLA}_{2}$ s from snake venom may be associated with fatty acids from the catalytic activity of cytosolic $\mathrm{PLA}_{2}\left(\mathrm{cPLA}_{2}\right)$ from the virus lipid envelope, once it is demonstrated that the enzymatic activity of the $\mathrm{CPLA}_{2}$ is required for the replication of various viruses [32]. In the case of the wild-type/normal viral protein, honeybee phospholipase A interacting residues were present on its C-terminal domain. Meanwhile, in the case of the mutant viral protein, residues of both the $\mathrm{N}$ - and C-terminal domains of honeybee phospholipase A were found to interact with the viral protein. Additionally, interacting residues of honeybee phospholipase A and snake phospholipase A were not conserved because snakes produce different types of venom depending on their type. Moreover, the degree of interaction of other molecules was low as compared to honeybee phospholipase A, and thus we consider it as the best possible candidate antiviral molecule present among honeybee venom proteins.

The antiviral effect of phospholipase A2 is already reported in the literature, but this in silico study will further enhance antiviral therapy using the phospholipase A2 enzyme from honeybee venom. According to our knowledge, this is the first report of a honeybee in silico study against EBOV and its mutant pathogenic strain.

The current study is unique in that it is the first to illustrate how the Ebola virus spike protein interacts with honeybee venom proteins. This research will be useful in the future since it will allow researchers to work on it and produce useful findings. On the other hand, the major drawback of this study is that it is merely an in silico study, with no information on how to deliver honeybee venom enzymes to patients.

\section{Materials and Methods}

In the current in silico study, protein homology modeling of honeybee venom peptides and proteins, as well as wild-type and mutant EBOV spike proteins, was conducted using RaptorX online tools. RaptorX is a template-based protein structure modeling server. It requires a protein sequence in FASTA format and provides a 3D structure in PDB format [33]. Models with a high confidence score (CS score) were selected.

The protein sequence of all the venom peptides and proteins and the EBOV spike virus was identified from the UniProt database [34]. Urbanowicz, 2016, reported mutation $(\mathrm{A} 82 \mathrm{~V}+\mathrm{P} 375 \mathrm{~S})$ of EBOV in [35]. 
Predicted 3D models were verified using the PROCHEK tool with default conditions [36], which provides results in the form of a Ramachandran plot. Results of the PROCHEK tool are available in the Supplementary File S1. Three-dimensional structures were visualized using Chimera1.13.1 [37]. For protein-protein docking, the online PatchDock tool was used using default conditions. The PatchDock technique performs protein structure prediction of both "protein-protein" and "protein-small molecule" docking. The inputs to PatchDock servers are either protein structures or PDB codes. The methods behind the server are very effective and allow large-scale docking experiments [38].

PatchDock results were edited using the offline tool PDB Editor to change the chain IDs of the docked proteins, and then the edited PDBs were visualized through the offline Java-based software LigPlot + v2.1 [39], with the results subsequently being interpreted.

\section{Conclusions}

The Ebola virus pandemic has created a stark landscape in the social, health and economic spheres. The lethality of the virus has taken many lives. There is an urgency to curb the outbreak of Ebola in Africa. In this context, the findings of this computational study indicate that phospholipase A2 from honeybee venom can be considered for prospective antiviral drugs against Ebola virus. Nevertheless, further experimental validation is required to substantiate the findings. Based on our knowledge, this in silico study is the first study of normal and mutant $E B O V$ spike protein interactions with honeybee proteins.

Supplementary Materials: The following supporting information can be downloaded at: https: / / www.mdpi.com/article/10.3390/biologics2010003/s1, File S1: 3D model validation proof by Ramachandran Plots.

Author Contributions: Conceptualization, M.M., M.A.K. and A.F.; data curation, M.A.K. and M.A.A.H.; investigation, A.F. and M.M.; methodology, A.F. and M.M.; project administration, A.F.; software, M.M.; supervision, A.F.; validation, A.J.A.; writing—original draft, M.M.; writing—review and editing, M.M., M.A.M. and A.F. All authors have read and agreed to the published version of the manuscript.

Funding: This research received no external funding.

Institutional Review Board Statement: Not applicable.

Informed Consent Statement: Not applicable.

Acknowledgments: We are grateful to all the laboratory members who helped in current in silico study.

Conflicts of Interest: The authors declare no conflict of interest.

\section{References}

1. Chen, J.; Guan, S.M.; Sun, W.; Fu, H. Melittin, the major pain-producing substance of bee venom. Neurosci. Bull. 2016, 32, $265-272$. [CrossRef] [PubMed]

2. Boldrini-Franca, J.; Cologna, C.T.; Pucca, M.B.; Bordon, K.D.C.F.; Amorim, F.G.; Anjolette, F.A.P.; Arantes, E.C. Minor snake venom proteins: Structure, function and potential applications. Biochim. Biophys. Acta (BBA)-Gen. Subj. 2017, 1861, 824-838. [CrossRef]

3. Ferreira, R.S.; Sciani, J.M.; Marques-Porto, R.; Lourenco, A.; Orsi, R.D.; Barraviera, B. Africanized honey bee (Apis mellifera) venom profiling: Seasonal variation of melittin and phospholipase A(2) levels. Toxicon 2010, 56, 355-362. [CrossRef]

4. Li, D.; Kim, W.; Shin, D.; Jung, Y.; Bae, H.; Kim, S.K. Preventive effects of bee venom derived phospholipase a2 on oxaliplatininduced neuropathic pain in mice. Toxins 2016, 8, 27. [CrossRef]

5. Bausch, D.G.; Schwarz, L. Outbreak of Ebola virus disease in Guinea: Where ecology meets economy. PLoS Negl. Trop. Dis. 2014, 8, e3056. [CrossRef] [PubMed]

6. Bedford, T.; Malik, H.S. Did a single amino acid change make Ebola virus more virulent? Cell 2016, 167, 892-894. [CrossRef]

7. WHO. Ebola Situation Report; W.H. Organization: Geneva, Switzerland, 2016.

8. Ogawa, H.; Miyamoto, H.; Nakayama, E.; Yoshida, R.; Nakamura, I.; Sawa, H.; Takada, A. Seroepidemiological prevalence of multiple species of filoviruses in fruit bats (Eidolon helvum) migrating in Africa. J. Infect. Dis. 2015, 212, S101-S108. [CrossRef] [PubMed] 
9. Moncla, L.H.; Zhong, G.; Nelson, C.W.; Dinis, J.M.; Mutschler, J.; Hughes, A.L.; Friedrich, T.C. Selective bottle-necks shape evolutionary pathways taken during mammalian adaptation of a 1918-like avian influenza virus. Cell Host Microbe 2016, 19, 169-180. [CrossRef] [PubMed]

10. Ng, M.; Ndungo, E.; Kaczmarek, M.E.; Herbert, A.S.; Binger, T.; Kuehne, A.I.; Chandran, K. Filovirus receptor NPC1 contributes to species-specific patterns of ebolavirus susceptibility in bats. Elife 2015, 4, e11785. [CrossRef]

11. Carroll, M.W.; Matthews, D.A.; Hiscox, J.A.; Elmore, M.J.; Pollakis, G.; Rambaut, A.; Günther, S. Temporal and spatial analysis of the 2014-2015 Ebola virus outbreak in West Africa. Nature 2016, 524, 97-101. [CrossRef]

12. Gire, S.K.; Goba, A.; Andersen, K.G.; Sealfon, R.S.; Park, D.J.; Kanneh, L.; Sabeti, P.C. Genomic surveillance elucidates Ebola virus origin and transmission during the 2014 outbreak. Science 2014, 345, 1369-1372. [CrossRef] [PubMed]

13. Ladner, J.T.; Wiley, M.R.; Mate, S.; Dudas, G.; Prieto, K.; Lovett, S.; Palacios, G. Evolution and spread of Ebola virus in Liberia, 2014-2015. Cell Host Microbe 2015, 18, 659-669. [CrossRef]

14. Quick, J.; Loman, N.J.; Duraffour, S.; Simpson, J.T.; Severi, E.; Cowley, L.; Carroll, M.W. Real-time, portable genome sequencing for Ebola surveillance. Nature 2016, 530, 228-232. [CrossRef] [PubMed]

15. Simon-Loriere, E.; Faye, O.; Faye, O.; Koivogui, L.; Magassouba, N.; Keita, S.; Sall, A.A. Distinct lineages of Ebola virus in Guinea during the 2014 West African epidemic. Nature 2015, 524, 102-104. [CrossRef] [PubMed]

16. Tong, Y.G.; Shi, W.F.; Liu, D.; Qian, J.; Liang, L.; Bo, X.-C.; Liu, J.; Ren, H.-G.; Fan, H.; Ni, M.; et al. Genetic diversity and evolutionary dynamics of Ebola virus in Sierra Leone. Nature 2015, 524, 93-96. [CrossRef]

17. Maslow, J.N. The cost and challenge of vaccine development for emerging and emergent infectious diseases. Lancet Glob. Health 2018, 6, e1266-e1267. [CrossRef]

18. Duffy, S. Why are RNA virus mutation rates so damn high? PLoS Biol. 2018, 16, e3000003. [CrossRef]

19. Mohammadi, P.P.; Fakhri, S.; Asgary, S.; Farzaei, M.H.; Echeverria, J. The signaling pathways, and therapeutic targets of antiviral agents: Focusing on the antiviral approaches and clinical perspectives of anthocyanins in the management of viral diseases. Front. Pharma 2019, 10, 1207. [CrossRef]

20. Carr, A.; Cooper, D.A. Adverse effects of antiretroviral therapy. Lancet 2000, 356, 1423-1430. [CrossRef]

21. Takashita, E. Influenza polymerase inhibitors: Mechanisms of action and resistance. Cold Spring Harb. Perspect. Med. 2020, 11, a038687. [CrossRef]

22. Fratellone, P.M.; Tsimis, F.; Fratellone, G. Apitherapy products for medicinal use. J. Altern Complement. Med. 2016, $22,1020-1022$. [CrossRef]

23. Socarras, K.M.; Theophilus, P.A.; Torres, J.P.; Gupta, K.; Sapi, E. Antimicrobial activity of bee venom and melittin against Borrelia burgdorferi. Antibiotics 2017, 6, 31. [CrossRef] [PubMed]

24. Perumal, S.R.; Gopalakrishnakone, P.; Thwin, M.M.; Chow, T.K.V.; Bow, H.; Yap, E.H.; Thong, T.W.J. Antibacterial activity of snake, scorpion and bee venoms: A comparison with purified venom phospholipase A2 en-zymes. J. Appl. Microb. 2007, 102, 650-659. [CrossRef] [PubMed]

25. Moreno, M.; Giralt, E. Three valuable peptides from bee and wasp venoms for therapeutic and biotechnological use: Melittin, apamin and mastoparan. Toxins 2015, 7, 1126-1150. [CrossRef]

26. Uddin, M.B.; Lee, B.H.; Nikapitiya, C.; Kim, J.H.; Kim, T.H.; Lee, H.C.; Kim, C.J. Inhibitory effects of bee venom and its components against viruses in vitro and in vivo. J. Microb. 2016, 54, 853-866. [CrossRef]

27. Filkin, S.Y.; Lipkin, A.V.; Fedorov, A.N. Phospholipase superfamily: Structure, functions, and biotechnological applications. Biochemistry 2020, 85, 177-195. [CrossRef] [PubMed]

28. Méndez, R.; Bonilla, F.; Sasa, M.; Dwyer, Q.; Fernández, J.; Lomonte, B. Proteomic profiling, functional characterization, and immunoneutralization of the venom of Porthidium porrasi, a pitviper endemic to Costa Rica. Acta Trop. 2019, 193, 113-123. [CrossRef] [PubMed]

29. Teixeira, S.C.; Borges, B.C.; Oliveira, V.Q.; Carregosa, L.S.; Bastos, L.A.; Santos, I.A.; Lopes, D.S. Insights into the antiviral activity of phospholipases A2 (PLA2s) from snake venoms. Int. J. Biol. Macromol. 2020, 164, 616-625. [CrossRef]

30. Cecilio, A.B.; Caldas, S.; De Oliveira, R.A.; Santos, A.S.B.; Richardson, M.; Naumann, G.B.; Schneider, F.S.; Alvarenga, V.G.; Estevão-Costa, M.I.; Fuly, A.L.; et al. Molecular Characterization of Lys49 and Asp49 Phospholipases A2 from Snake Venom and Their Antiviral Activities against Dengue virus. Toxins 2013, 5, 1780-1798. [CrossRef]

31. Mora-Obando, D.; Fernandez, J.; Montecucco, C.; Gutierrez, J.M.; Lomonte, B. Synergism between basic Asp49 and Lys49 phospholipase A2 myotoxins of viperid snake venom in vitro and in vivo. PLoS ONE 2014, 9, e109846. [CrossRef]

32. Vijay, R.; Hua, X.; Meyerholz, D.K.; Miki, Y.; Yamamoto, K.; Gelb, M.; Murakami, M.; Perlman, S. Critical role of phospholipase A2 group IID in age-related susceptibility to severe acute respiratory syndrome-CoV infection. J. Exp. Med. 2015, 212, 1851-1868. [CrossRef]

33. Källberg, M.; Wang, H.; Wang, S.; Peng, J.; Wang, Z.; Lu, H.; Xu, J. Template-based protein structure modeling using the RaptorX web server. Nat. Protoc. 2012, 7, 1511-1522. [CrossRef]

34. UniProt Consortium. UniProt: A hub for protein information. Nucleic Acid Res. 2015, 43, D204-D212. [CrossRef]

35. Urbanowicz, R.A.; McClure, C.P.; Sakuntabhai, A.; Sall, A.A.; Kobinger, G.; Müller, M.A.; Ball, J.K. Human ad-aptation of Ebola virus during the West African outbreak. Cell 2016, 167, 1079-1087. [CrossRef]

36. Laskowski, R.A.; MacArthur, M.W.; Moss, D.S.; Thornton, J.M. PROCHECK: A program to check the stereochemical quality of protein structures. J. Appl. Crystallogr. 1993, 26, 283-291. [CrossRef] 
37. Pettersen, E.F.; Goddard, T.D.; Huang, C.C.; Couch, G.S.; Greenblatt, D.M.; Meng, E.C.; Ferrin, T.E. UCSF Chimera-A visualization system for exploratory research and analysis. J. Comput Chem. 2004, 25, 1605-1612. [CrossRef] [PubMed]

38. Schneidman-Duhovny, D.; Inbar, Y.; Nussinov, R.; Wolfson, H.J. PatchDock and SymmDock: Servers for rigid and symmetric docking. Nucleic Acids Res. 2005, 33, W363-W367. [CrossRef] [PubMed]

39. Laskowski, R.A.; Swindells, M.B. LigPlot+: Multiple ligand-protein interaction diagrams for drug discovery. J. Chem. Inf. Model. 2011, 51, 2778-2786. [CrossRef] [PubMed] 